\title{
Size and emotion or depth and emotion? Evidence, using Matryoshka (Russian) dolls, of children using physical depth as a proxy for emotional charge
}

\author{
Andrew K Dunn*, Nicola Taylor and Thom Baguley
}

\begin{abstract}
Background: The size and emotion effect is the tendency for children to draw people and other objects with a positive emotional charge larger than those with a negative or neutral charge. Here we explored the novel idea that drawing size might be acting as a proxy for depth (proximity).

Methods: Forty-two children (aged 3-11 years) chose, from 2 sets of Matryoshka (Russian) dolls, a doll to represent a person with positive, negative or neutral charge, which they placed in front of themselves on a sheet of A3 paper.

Results: We found that the children used proximity and doll size, to indicate emotional charge.

Conclusions: These findings are consistent with the notion that in drawings, children are using size as a proxy for physical closeness (proximity), as they attempt with varying success to put positive charged items closer to, or negative and neutral charge items further away from, themselves.
\end{abstract}

Keywords: Size and emotion effect, Children's drawings, Proximity, Depth, Attachment, Representation

\section{Background}

Children understand emotions in drawings from an early age $(\approx 4$ years). They begin representing emotions in the form of simple lines (smiles or frowns on faces) from about 5 years onwards, a skill that becomes increasingly more complex (Cox 2005, p.148; Ives 1984; Morra et al. 1994; Winston et al. 1995). Young children also use object size to represent emotion in their drawings (Cox 2005, p.145). The tendency to use object size as an indicator of emotional charge (positive or negative feelings) towards people and other objects is called the size and emotion effect (Cox 2005, p.145). Typically, children $(\approx 4-11$ years) draw positive charged (nice or pleasant or liked) objects (e.g. people, apples, dogs) bigger than negative charged (nasty or unpleasant or disliked) and neutral charged (e.g. trees, tables, cars) objects (Burkitt et al. 2003; Thomas et al. 1989). Negative charged objects are usually drawn the same size as neutral charge objects, although they are sometimes drawn as smaller than neutral ones (Burkitt

* Correspondence: andrew.dunn@ntu.ac.uk

Nottingham Trent University, Burton Street, Nottingham NG1 4BU, UK et al. 2003, 2004). The effect is sensitive to factors both methodological (e.g. available space when drawing multiple objects on the same page, rather than separate pages, affects object placement and relative object size) and developmental (such as changes in the ability to plan, associated with typical development in the frontal lobes and formal education). Accordingly, it has been shown that such factors can lead to a reversal of the effect (i.e. negative figure > positive figure; Cotterill \& Thomas 1990; Jolley 1995), loss of the effect (e.g. a focus on realism over expression, in older children - Cox 2005, p.145) or else inconsistency in individual performance over time (Cox 2005, p.147; Jolley 1995; Strange et al. 2010). Furthermore, no effect has been found where very strong negative or positive feelings might be expected to be expressed in drawings such as in patients with depression (Joiner et al. 1996) or in children who have experienced military conflict (Jolley \& Vulic-Prtoric 2001).

There is a very clear history of inappropriate interpretation in the use of children's drawings as a diagnostic tool (Cox 2005, p.261). Indeed it is not clear that drawings are 
the best way to explore extreme emotional stress (Joiner \& Schmidt 1997) and evidence for their use as a clinical diagnostic tool does not appear to exist (Flanagan \& Motta 2007). Thus the absence of a size and emotion effect for extreme emotion should not be taken as evidence that the children are not trying to express emotional charge in drawings. Moreover, inconsistencies in the presence or absence of the size and emotion effect are typically associated with methodological factors (such as available drawing space). It has also been pointed out that some analyses may be underpowered, there by missing the effect. For example, although Jolley (1995) employed a repeated measures design in his work, he used a fairly small sample size (see Burkitt et al. 2003). In addition, since children are often not being asked to directly manipulate size in the drawing tasks then it is likely that the observed effects will never be very large (they are in effect a shadow cast by the task). Thus the evidence from our own lab (Rajput, M: Internal representation of affective preferences for liked, disliked and neutral human figures drawings: representation as size or distance as a function of emotional preference. Unpublished.) and elsewhere (e.g. Cleeve \& Bradbury 1992; Craddick 1963; Fox \& Thomas 1990; Ives Ives 1984; Sechrest \& Wallace 1964), demonstrates that where attention is paid to methodology, typically developing children do tend to modulate object drawing size with emotional charge (see Cox 2005, p.145-148; Burkitt et al. 2003, 2004; Thomas et al. 1989).

Whilst it is generally assumed that drawing size acts as a proxy for emotional content - where bigger equals more positive - it is not clear why children might do this (Cox 2005, p.147). Jolley (1995) proposed an appetitive-defence mechanism, such that size might be related to a child's identification with the object. That is to say children increase object drawing size to identify more closely with positive charge objects and decrease object drawing size to reduce the threat from negative charge objects. Whilst plausible, Jolley's account is problematic in that it does not easily explain the inconsistencies in the literature (such as why the effect might sometimes be reversed). Nor does it properly address why the children would use size to identify with, or reduce threat from, the emotionally charged objects in the first place.

It remains a moot point as to why children typically modulate drawing size for emotion. However, a change in drawing size might reflect a desire to show preference (emotional charge) by placing the objects in depth. Specifically, differences in relative object (drawing) size might be an attempt to represent associated retinal size at different distances (perceived depth) or physical closeness (proximity), though these need not be mutually exclusive. Furthermore this idea is not inconsistent with a notion of size as an index of closeness or threat reduction (c.f. Jolley 1995): children may be trying to identify by bringing close (thereby increasing visual size) the positive charged object, or reduce threat by moving away (thereby reducing visual size) the negative charge item.

Representing depth in drawings can be difficult, even for adults who have received some training (Cox 2005, p.116). Certainly young children are aware of and can represent depth in 2-dimensional (2D) drawings (Cox 2005, p.118). Thus at 3-4 years children seem to understand that object size is reduced in distant objects (Pillow \& Flavell 1986) and can use size judgements to determine object depth in pre-drawn pictures, though not necessarily in their own drawings (Perara \& Cox 2000). By 5 years children can also use object height (position on the page) to indicate distance: distant objects are placed further up the page than nearer objects (Freeman et al. 1977). They also position multiple objects above or below each other to convey depth (Cox \& Perara 2001). However, children do not spontaneously draw objects in depth until they are around 7 years (Cox 1986) and it is not until 8-9 years that children combine size and height (Cox \& Perara 2001), use diverging and converging lines (Cox \& Littlejohn 1995), or use foreshortening (Nicholls 1995) with any success or consistency in their drawings, unless being prompted to do so.

We propose that that the size and emotion effect might be an attempt to represent physical distance between the child and the object in relation to its (the object's) emotional charge (near $=$ big = positive charge; further away $=$ small $=$ negative charge). Given that representing depth in drawings can be difficult, we further suggest that inconsistencies or reversals of the effect might reflect the difficulties children experience with producing depth or proximity cues in their drawings. Here we tested our novel idea, in 3-dimensional space, by using a task that was analogous to the size and emotion drawing procedure. In our task we asked children to select a doll to represent a person with positive charge, a doll to represent a person with negative charge, and a doll to represent a person with neutral charge, which after each selection they then had to place on a sheet of A3 paper in front of them. The dolls we used were 2 (7 piece) sets of Matryoshka (Russian) dolls that were highly similar in design and size across pairs. We reasoned that by using simple human figures that maintained a similar representation but that varied in size we would reduce some of the task difficulties associated with depth representation (in drawings) whilst allowing for simultaneous changes in size (height or circumference) and distance.

We hypothesized that if the children are using actual size to indicate emotional charge then they should consistently chose bigger (taller and/or bigger base circumference) dolls to represent positive charge, relative to dolls chosen to represent negative or neutral charge. If the children are using physical distance (proximity) to represent charge, then they should place positive charged dolls closer to themselves than negative or neutral char- 
ged dolls, irrespective of doll size (height or base circumference).

\section{Methods}

\section{Participants and design}

Forty-two children ( 22 boys \& 20 girls; median age $=5$ years 6 months; range 3-11 years), from 2 locations (a nursery school class and a number of classes in a primary school, both based in Derbyshire), took part in this experiment. This was an opportunistic sample, available at the time of testing, towards the latter half of the school year. Following clearance by the Social Science ethics board (Nottingham Trent University - reference N Taylor 18.01.11) permission was then sought from the schools. Once obtained, we wrote to the parents asking for their permission in which we explained the task and asked them to return an opt-form if they did not want their child to take part. Testing took place approximately 1 week later. At test no child was made to take part if they did not want to, or without appropriate consent.

Since this was an opportunity sample we did not formally control for age. However, we did informally explore individual age-group related performance across the (wide) age range of the sample. We did this by plotting trend-lines across age-group data graphs for each of the response measures. Formal analysis of the mean charge selection data, for each measure, was carried out using one-way between subjects ANOVA. By definition age and other individual differences are incorporated into the subjects term (Baguley 2012a, p.625-627). Thus including age as a covariate in this analysis has no additional influence on the subsequent output ( $F$ ratios are unaffected). Both formal and informal observations are reported in the Results section.

\section{Apparatus}

Our decision to use Matryoshka dolls for this task was largely practical. First they are an engaging, 3D form that varies in size whilst maintain a relatively consistent simple human representation. Second we wanted more than one set of dolls that were highly similar (in design and size across pairs) so that the children could chose the same size dolls to represent different emotional charge. We also wanted to have a range of sizes but did not want to overload the child with too many options. We therefore chose to use 2 sets of 7 piece dolls because we felt they represented the best compromise for these criteria whilst allowing for the children to choose a similar looking doll of the same size for different charges. Details of the dolls and an image of one set are provided in Table 1 and Figure 1, respectively. Note that the level of painted detail diminishes with size.

\section{Procedure}

The children were tested individually (by author NT) on site, in a quiet area away from any other children. Each
Table 1 Summary of Matryoshka doll measurements (sets 1 and 2)

\begin{tabular}{cccccc}
\hline SET & Doll & Height & $\begin{array}{c}\text { Widest } \\
\text { circumference }\end{array}$ & $\begin{array}{c}\text { Circumference } \\
\text { base }\end{array}$ & Diameter \\
\hline 1 & 1 & $2.90 \mathrm{~cm}$ & $5.10 \mathrm{~cm}$ & $4.08 \mathrm{~cm}$ & $1.30 \mathrm{~cm}$ \\
1 & 2 & $5.00 \mathrm{~cm}$ & $7.70 \mathrm{~cm}$ & $5.96 \mathrm{~cm}$ & $1.90 \mathrm{~cm}$ \\
1 & 3 & $6.60 \mathrm{~cm}$ & $10.90 \mathrm{~cm}$ & $7.85 \mathrm{~cm}$ & $2.50 \mathrm{~cm}$ \\
1 & 4 & $8.80 \mathrm{~cm}$ & $14.00 \mathrm{~cm}$ & $10.36 \mathrm{~cm}$ & $3.30 \mathrm{~cm}$ \\
1 & 5 & $10.50 \mathrm{~cm}$ & $18.10 \mathrm{~cm}$ & $12.88 \mathrm{~cm}$ & $4.10 \mathrm{~cm}$ \\
1 & 6 & $12.80 \mathrm{~cm}$ & $21.20 \mathrm{~cm}$ & $16.65 \mathrm{~cm}$ & $5.30 \mathrm{~cm}$ \\
1 & 7 & $15.70 \mathrm{~cm}$ & $26.70 \mathrm{~cm}$ & $23.56 \mathrm{~cm}$ & $7.50 \mathrm{~cm}$ \\
2 & 1 & $3.0 \mathrm{~cm}$ & $5.00 \mathrm{~cm}$ & $4.71 \mathrm{~cm}$ & $1.50 \mathrm{~cm}$ \\
2 & 2 & $4.80 \mathrm{~cm}$ & $7.80 \mathrm{~cm}$ & $5.60 \mathrm{~cm}$ & $1.80 \mathrm{~cm}$ \\
2 & 3 & $6.70 \mathrm{~cm}$ & $10.70 \mathrm{~cm}$ & $7.53 \mathrm{~cm}$ & $2.40 \mathrm{~cm}$ \\
2 & 4 & $8.50 \mathrm{~cm}$ & $14.00 \mathrm{~cm}$ & $10.68 \mathrm{~cm}$ & $3.40 \mathrm{~cm}$ \\
2 & 5 & $10.90 \mathrm{~cm}$ & $17.70 \mathrm{~cm}$ & $12.56 \mathrm{~cm}$ & $4.00 \mathrm{~cm}$ \\
2 & 6 & $13.00 \mathrm{~cm}$ & $21.50 \mathrm{~cm}$ & $16.02 \mathrm{~cm}$ & $5.10 \mathrm{~cm}$ \\
2 & 7 & $16.80 \mathrm{~cm}$ & $26.20 \mathrm{~cm}$ & $24.81 \mathrm{~cm}$ & $7.90 \mathrm{~cm}$ \\
\hline
\end{tabular}

child was seated at a table such that the table was about level with the middle of their stomach and that they could see and reach freely across the space around them. Before testing each child was able to look at the dolls and to handle them if they wished.

Having been seated, it was explained to each child that in this task they were going to be asked to look carefully at the dolls and then choose (one at a time) 3 dolls to represent someone they liked (positive charge), someone they did not like (negative charge) and someone that was just a person, that they neither liked nor disliked (neutral charge). The dolls were then placed one at a time in height order (height order direction randomised for each child) in front of them, along the back edge of a sheet of A3 paper. Next the children were told that each time they chose a doll, they should place it on the piece

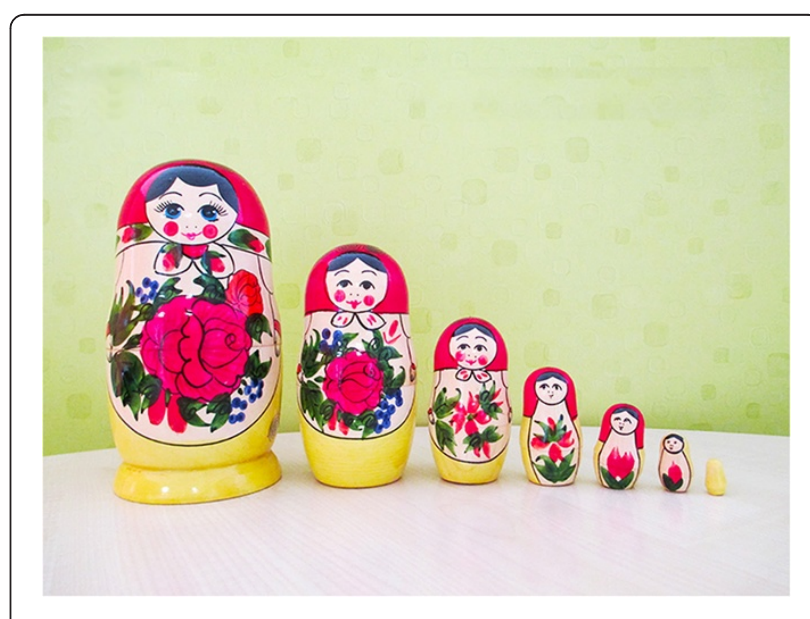

Figure 1 Sample set of Matroyoshka (Russian) dolls. 
of paper in front of them, and that they could choose any available doll and place it anywhere on the paper. Before beginning the task, the experimenter made sure that the children understood what they were being asked to do and that they still wanted to take part. All children agreed to take part in the task.

At test, each child was given a scripted set of selection instructions, with the order of doll charge selection being randomised so as to avoid charge order bias. The instructions were as follows:

Positive charge doll: "Please can you think of a person you like, once you have thought of somebody can you choose one of those dolls in front of you that could be the person that you like? Once you have chosen the doll could you please place it anywhere on the piece of paper in front of you?"

Negative charge doll: "Please can you think of a person you do not like, once you have thought of somebody can you choose one of those dolls in front of you that could be that person that you do not like? Once you have chosen the doll could you please place it anywhere on the piece of paper in front of you?'

Neutral charge doll: "Please can you think of a neutral person, just a person, it can be anyone at all. Once you have thought of somebody can you choose one of those dolls in front of you to be that person? Once you have chosen the doll could you please place it anywhere on the piece of paper in front of you?"

We used standardised instructions so as to maintain consistency in what was being asked, however, we were aware that some children might not fully understand what was meant by like, dislike, or neutral. For this reason we took great pains both before and during test to ensure that that the children were as clear as they could be about the terms being used. For example, where a child did not understand the instructions, they were reassured, the instructions were then repeated and the child was encouraged to make a selection to match the condition. In practice all of the children, even the very young ones, appeared to understand what was being asked of them and what the terms being used meant; they required very little prompting or additional explanation or support during test.

Following the placement of the dolls (each selected doll remained in position until the task was completed), three measures were obtained: (1) Doll height - base to top (cm), (2) Doll base circumference $(\mathrm{cm})$ and (3) Physical distance from doll to child $(\mathrm{cm})$ - a circle was drawn around each doll and the distance from the centre point to the middle of the child's seated position was measured.

\section{Results}

The data set indicated that there is a tendency for positive charged dolls to be slightly bigger (taller and broader) and be placed closer to the child than neutral or negative charged dolls (see Table 2). However, there does not appear to be any evidence of age related effects across the sample in any of the tasks. Individual performance is variable but the general trend (as indicated by the trend line) across the age-groups is relatively flat in all cases (see Figure 2).

To explore these data formally we ran 3 one-way repeated measures ANOVAs (height; circumference; distance), each with 3 levels (positive charge, negative charge, neutral charge). The analyses for height $(F(2,82)=0.68$; $\left.M S E=23.65 ; \quad P=0.51 ; \quad \eta_{G}^{2}=0.04\right)$ and circumference $\left(F(2,82)=1.11 ; M S E=50.03 ; P=0.34 ; \eta_{G}^{2}=0.07\right)$ were not significant. However the analysis for distance was significant $\left(F(2,82)=5.26 ; M S E=15.54 ; P=0.01 ; \eta_{G}^{2}=0.086\right)$. The patterns of results are presented in Figure 3 with Cousineau-Morey style difference-adjusted confidence intervals (Baguley 2012b). These are adjusted so that means with non-overlapping error bars are different with approximately 95\% confidence. As can be seen in Figure 3(c) there is a significant difference between the positive charged dolls and both the negative and neutral charged dolls $(P<0.05)$ but not between the negative and neutral charged dolls $(P>0.05)$.

\section{Discussion}

In considering the literature on the size and emotion effect in children's drawings we were motivated to propose that size might be acting as a proxy for depth (or closeness) in children's drawings and that some of the inconsistencies in the findings might have occurred because the children are struggling to represent 3-demensions in a 2-dimentional drawing task. We operationalized this idea by creating an analogue of the drawing task using Russian dolls. This analogous task allowed the children to modulate height, width and distance, whilst limiting some of the methodological difficulties usually associated with the drawing task (see above and Cox 2005, p.146-147).

Table 2 Mean and standard deviations for each of the three measures (height, circumference and distance)

\begin{tabular}{lcccc}
\hline Charge & & Height $(\mathbf{c m})$ & Circumference $(\mathbf{c m})$ & Distance $(\mathbf{c m})$ \\
\hline Positive & M (SD) & 10.16 & 14.65 & 12.93 \\
& & $(5.14)$ & $(7.54)$ & $(5.40)$ \\
Negative & $M(S D)$ & 9.08 & 12.80 & 15.44 \\
& & $(5.01)$ & $(7.51)$ & $(4.63)$ \\
Neutral & $M(S D)$ & 9.1 & 12.55 & 15.25 \\
& & $(3.53)$ & $(4.83)$ & $(4.46)$ \\
\hline
\end{tabular}




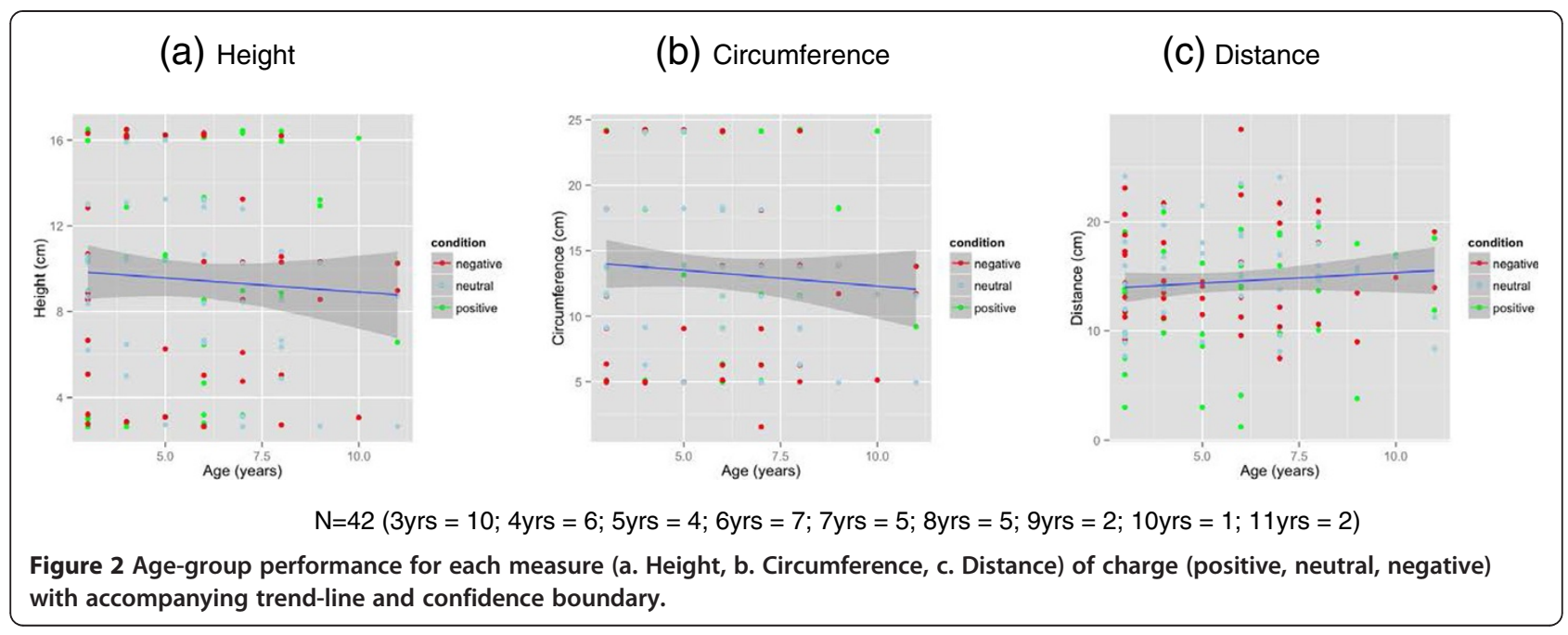

The results of our experiment indicated that the children were not consistently selecting taller or wider based dolls to represent charge. Instead they were manipulating depth to represent charge, by placing the positive charged dolls physically closer to themselves than the negative or neutral charged dolls. These findings are consistent with our distance (proximity) proposal and the notion that size might be acting as a proxy for physical closeness in 2dimentional figure drawings. We believe that our findings offer further insight into understanding the size and emotion effect. To whit we suggest that, having taken into account the problem of representing depth in drawings, the size and emotion effect in children's drawings might be seen as a proximity and emotion effect, in which children use object size (with various success) as a proxy for physical depth (proximity).

We recognise that our approach is not without issue. For example, it is possible that our task is not suitably sensitive to underlying developmental differences across the (wide) age range of our sample (e.g. DeLoache 2000; Karmiloff-Smith 1995, p.10). Certainly there is age related variation in many types of cognitive development, however there can be differences in behavioural expression (where a U-shaped pattern is often observed) and underlying representational change (where the pattern might be positively linear) - see Karmiloff-Smith, (1995, p.19). Thus it can be seen in the drawing literature that a child's ability to understand and represent emotion becomes more sophisticated and expressive with increased age. Accordingly, whilst their ability to express emotion in their drawings first increases, there is often a U-shaped dip (or a plateau) in emotional expression that coincides with schooling and a drive towards expressing realism, at around 5-9 years. This is then followed by a steady increase in emotional expression up to about 14 years (See Cox 2005, p.148-151).

We also recognise that even if the doll task reduced some aspects of cognitive demand in relation to depth

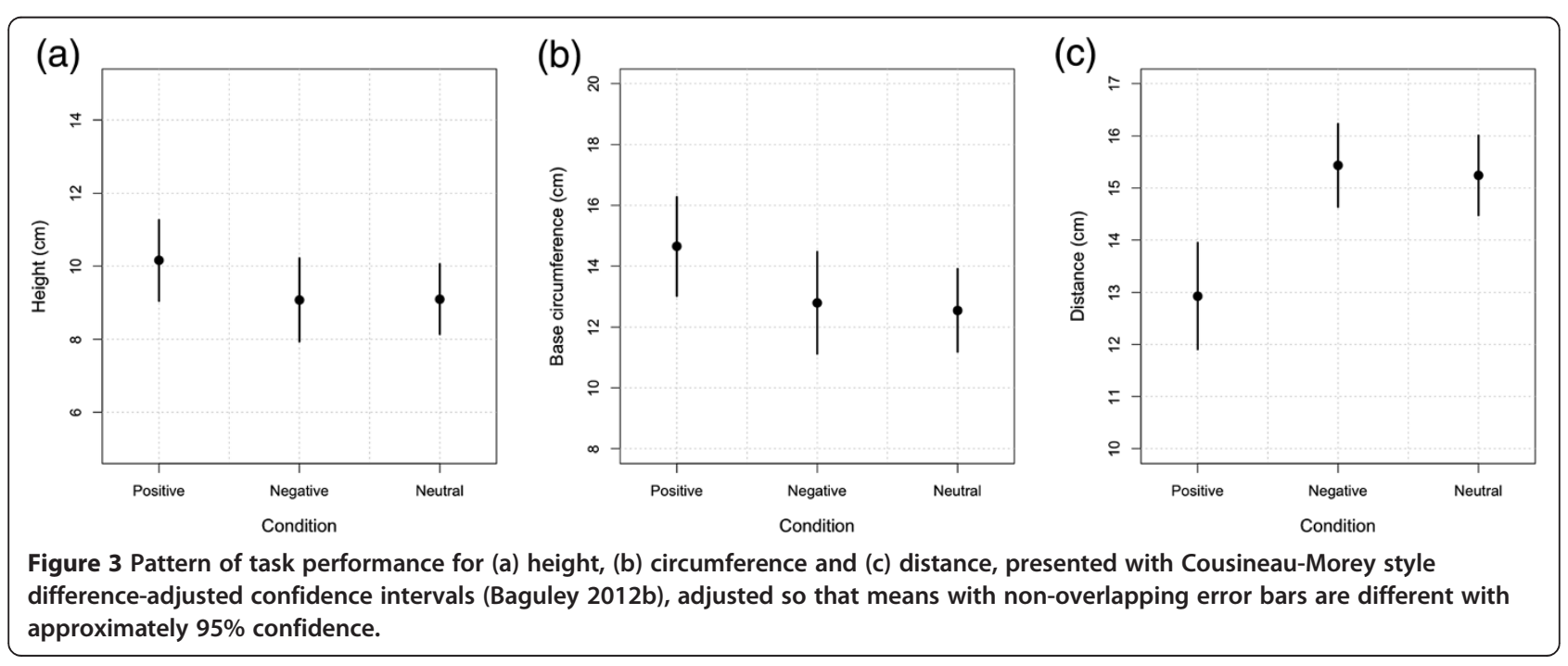


representation, the task might still be demanding in terms of dual representation. That is to say it may have been particularly difficult for the younger children to hold a dual representation of the doll, as a doll, and as a symbolic representation of the person they associated with the emotional charge (e.g. DeLoache 2000). Likewise, some children (especially the younger ones) may not have fully understood the task instructions, particularly for the neutral charge figures. Certainly, some of the children in this task were very young (3-4 years) and other studies (e.g. Burkitt, et al. 2003) have used more user-friendly terminology.

However, we did not see any obvious developmental patterns in the spread of individual responses across the age range of our sample. Moreover differences in age would have been incorporated in the subjects term of the ANOVA thus rendering unnecessary further analysis of age as a covariate or additional factor. Further, whilst very young children do have difficulty with dual representation, by $2 \frac{1}{2}$ years many children will readily engage in symbolic pretence in their games (e.g. using a wooden block as a phone) and by 3-4 years of age most children find dual representation relatively unproblematic, although this may vary from child to child (DeLoache 2000). Concomitantly, at testing there did not appear to be any difficulties with the task instructions. However, even if some children did not fully understand what was meant by, for example '...a neutral person.', the results show that positive charged dolls were positioned physically closer than negative charged dolls: differentiating between the positive and negative charges is consistent with the pertinent literature even if the variable being manipulated (c.f. distance rather than size) is not. In short, we are confident that age did not impact on task performance.

One advantage of our approach is that we limited methodological issues related to crowding and planning whilst maintaining the core matter of exploring the representation of emotional charge in objects. For example, we managed to limit problems of space and crowding typically associated with multiple object representation in drawings (see above): unlike in a drawing where the objects can freely vary, potentially influencing the amount of available space and the size of the next object drawn, doll size (height and width) variation is fixed at each doll interval. Indeed if the children were using size to represent charge (as they appear to do in drawings) then space was not likely to be a problem because there was more than enough space to place 3 large dolls on the paper. Notwithstanding, available space might have been an issue in relation to how far away the children could place the dolls. Note that available space (in this regard) is also impacted on by how far the child could reach and the perimeter of the table. Fortunately there was plenty of space beyond the edges of the paper to the perimeter of the table and children could have, but did not in practice, place the dolls outside of the paper area. Also the dolls were not necessarily placed directly in front of the child, but instead could appear either side of the child's mid-line. Thus given the results observed here, space (and likely associated planning) does not seem to be an issue.

One final point of concern (raised by one of our reviewers) relates to the appearance of our doll stimuli. Although we are confident that our compromise on the number of dolls ( 2 sets of 7) allowed sufficient range of choice in this experiment, we do recognise that the dolls are ostensibly female in design and that this might have impacted upon performance. For example, the children might be associating the female dolls with a positive maternal representation irrespective of the task instructions. Certainly this is possible. However such an association might also strengthened the salience of the positive charge dolls thereby distinguishing them from the other emotional charges. This might even make it easier to hold a dual representation of the doll and its associate person of positive charge. However it remains uncertain what impact, if any, the sex or gender of the doll might have had. Moreover, whilst this may be an interesting avenue of further research, it does not readily explain why the children are placing the positive charged dolls physically closer to themselves rather than selecting a bigger (wider or taller) doll instead.

Finally, without further research it remains unclear as to why children would want to convey emotional charge by manipulating size or proximity. However, it is conceivable that the distancing effects observed here might reflect innate aspects of attachment, or the processes of attachment, namely safe-base proximity behaviour (e.g. Ainsworth 1973, p.45; Bowlby 1969, p.40). Safe-base behaviours are innate, occur very early on and persist throughout the lifespan. This might help to explain why the children use depth to represent positive, negative or neutral charge objects. It may also explain why there is no obvious age related differences in these data. However, distancing effects might vary with attachment type, attachment stage and possibly even temperament. Similarly, there might also be cross-cultural differences in the size or presence of the effect as a function of the culture in which the child is being raised. For example, there might be differences in the magnitude (or presence) of the effect in social situations when comparing between cultures that favour close proximity, increased emotion or physical contact, and cultures that that do not. Quite what those differences might be is at present unclear.

\section{Conclusions}

It has been shown here that when asked to select dolls taken from two sets of highly similar Matryoshka dolls, 
to represent a person with positive, negative or neutral charge, children aged between 3-11 years, place the positive charged dolls physically closer to them than the negative or neutral charged dolls. This finding is consistent with the hypothesised distance (proximity) proposal, supporting the notion that size might be acting as a proxy for physical closeness in figure drawings.

\section{Competing interests}

The authors declared that they have no competing interests.

\section{Authors' contributions}

AKD conceived and designed the experiment, carried out the analysis and interpretation of data and wrote most of the manuscript for publication. NT was involved in the initial design, collected all of the data and wrote an early draft of the methods section, TB carried out some additional data analysis, contributed to the interpretation of data and later drafts of the manuscript All authors read and approved the final manuscript

\section{Authors' information}

Nicola Taylor: Independent Researcher.

\section{Acknowledgements}

The authors would like to thank the schools, parents and children involved in this research. They would also like to thank all of the reviewers and the editor for their helpful and incisive comments on this manuscript.

Received: 22 April 2013 Accepted: 18 September 2013

Published: 29 October 2013

\section{References}

Ainsworth, MDS. (1973). The development of infant-mother attachment. In BM Caldwell \& HN Ricciuti (Eds.), Review of Child Development Research (Nol. 3, pp. 1-94). Chicago: University of Chicago Press.

Baguley, T. (2012a). Serious stats: A guide to advanced statistics for the behavioral sciences. Basingstoke: Palgrave.

Baguley, T. (2012b). Calculating and graphing within-subject confidence intervals for ANOVA. Behavior Research Methods, 44, 158-175.

Bowlby, J. (1969). Separation and Loss. Volume 1: Attachment. New York: Basic Books.

Burkitt, E, Barrett, M, \& Davis, A. (2003). The effect of affective characterizations on the size of children's drawings. British Journal of Developmental Psychology, 21, 565-584.

Burkitt, E, Barrett, M, \& Davis, A. (2004). The effect of affective characterizations on the use of size and colour in drawings produced by children in the absence of a model. Educational Psychology, 24, 315-343.

Cleeve, H, \& Bradbury, RJ. (1992). Children's productions and judgments of drawings of people of different importance. Seville: Poster presented at the 5th European Conference of Developmental Psychology.

Cotterill, A, \& Thomas, GV. (1990). Children's production and perception of drawings of emotionally significant topics. Poster presented at the forth European Conference on Developmental Psychology. Stirling, UK: University of Stirling.

Cox, MV. (1986). Cubes are difficult things to draw. British Journal of Developmental Psychology, 4, 341-345.

Cox, M. (2005). The pictorial world of the child. New York, NY US: Cambridge University Press.

Cox, MV, \& Littlejohn, K. (1995). Children's use of converging obliques in their perspective drawings. Educational Psychology, 15, 127-139.

Cox, MV, \& Perara, J. (2001). Children's use of height and size cues to depict a projective depth relationship in their pictures. Psychologia, 41, 171-182.

Craddick, RA. (1963). Size of Hallowe'en witch drawings prior to, on and after Hallowe'en. Perceptual and Motor Skills, 16, 235-238.

DeLoache, JS. (2000). Dual representation and young children's use of scale models. Child Development, 71, 329-338.

Flanagan, F, \& Motta, RW. (2007). Figure drawings: A popular method. Psychology in the Schools, 44, 257-270.

Fox, T, \& Thomas, GV. (1990). Children's drawings of an anxiety-eliciting topic: Effect on size of the drawing. British Journal of Clinical Psychology, 29, 71-81.

Freeman, NH, Eiser, C, \& Sayers, J. (1977). Children's strategies in producing 3-D relationships on a 2-D surface. Journal of Experimental Child Psychology, 23, 305-314.
Ives, W. (1984). The development of expressivity in drawing. British Journal of Educational Psychology, 54, 152-159.

Joiner, TE, \& Schmidt, KL. (1997). Drawing conclusions or not from drawings. Journal of Personality Assessment, 69, 476-481.

Joiner, TE, Schmidt, KL, \& Barnett, J. (1996). Size, detail, and line heaviness in children's drawings as correlates of emotional distress: (more) negative evidence. Journal of Personality Assessment, 67, 127-141.

Jolley, RP. (1995). Children's production and perception of visual metaphors for mood and emotion in line drawings and in art. Birmingham: Unpublished doctoral dissertation, University of Birmingham.

Jolley, RP, \& Vulic-Prtoric, A. (2001). Croatian children's experience of war is not reflected in the size and placement of emotive topics in their drawings. British Journal of Clinical Psychology, 40, 107-110.

Karmiloff-Smith, A. (1995). Beyond Modularity: A Developmental Perspective on Cognitive Science. Cambridge, Massachusetts: MIT Press.

Morra, S, Caloni, B, \& d'Amigo, MR. (1994). Working memory and the international depiction of emotions. Archives de Psychologie, 62, 71-87.

Nicholls, AL. (1995). Influence of visual projection on young children's depictions of object proportions. Journal of Experimental Child Psychology, 60, 304-326.

Perara, J, \& Cox, MV. (2000). The effect of background context on childrens' understanding of the spatial depth arrangement of objects in a drawing. Psychologia, 43, 144-153.

Pillow, BH, \& Flavell, JH. (1986). Intellectual realism: the role of children's interpretations of pictures and perceptual verbs. Child Development, 56, 664-670.

Sechrest, L, \& Wallace, J. (1964). Figure drawings and naturally occurring events. Journal of Educational Psychology, 55, 42-44.

Strange, D, Van Papendrecht, H, Crawford, E, Candel, I, \& Hayne, H. (2010). Size doesn't matter: emotional content does not determine the size of objects in children's drawings. Psychology, Crime \& Law, 16, 459-476.

Thomas, G, Chaigne, E, \& Fox, T. (1989). Children's Drawings of topics differing in significance: effects on size of drawing. British Journal of Developmental Psychology, 7, 321-331.

Winston, AS, Kenyon, B, Stewardson, J, \& Lepine, T. (1995). Children's sensitivity to expression of emotion in drawings. Visual Arts Research, 21, 1-14.

doi:10.1186/2050-7283-1-21

Cite this article as: Dunn et al:: Size and emotion or depth and emotion? Evidence, using Matryoshka (Russian) dolls, of children using physical depth as a proxy for emotional charge. BMC Psychology 2013 1:21.

\section{Submit your next manuscript to BioMed Central and take full advantage of:}

- Convenient online submission

- Thorough peer review

- No space constraints or color figure charges

- Immediate publication on acceptance

- Inclusion in PubMed, CAS, Scopus and Google Scholar

- Research which is freely available for redistribution 